\title{
A framework for comparative analysis of health systems: experiences from the Asia Pacific Observatory on Health Systems and Policies
}

\author{
Judith Mary Healy ${ }^{1}$, Shenglan Tang², Walaiporn Patcharanarumol ${ }^{3}$, Peter Leslie Annear ${ }^{4}$ \\ ${ }^{1}$ School of Regulation and Global Governance, Australian National University, Canberra, Australia, ${ }^{2}$ Duke Global Health Institute, \\ Duke Kunshan University, Kunshan, Jiangsu, China, ${ }^{3}$ International Health Policy Program, Ministry of Public Health, Nonthaburi, \\ Thailand, ${ }^{4}$ Nossal Institute for Global Health, University of Melbourne, Melbourne, Australia
}

Correspondence to: Dr Judith Mary Healy (judith.healy@anu.edu.au)

\begin{abstract}
Drawing on published work from the Asia Pacific Observatory on Health Systems and Policies, this paper presents a framework for undertaking comparative studies on the health systems of countries. Organized under seven types of research approaches, such as national case-studies using a common format, this framework is illustrated using studies of low- and middle-income countries published by the Asia Pacific Observatory. Such studies are important contributions, since much of the health systems research literature comes from high-income countries. No one research approach, however, can adequately analyse a health system, let alone produce a nuanced comparison of different countries. Multiple comparative studies offer a better understanding, as a health system is a complex entity to describe and analyse. Appreciation of context and culture is crucial: what works in one country may not do so in another. Further, a single research method, such as performance indicators, or a study of a particular health system function or component, produces only a partial picture. Applying a comparative framework of several study approaches helps to inform and explain progress against health system targets, to identify differences among countries, and to assess policies and programmes. Multi-method comparative research produces policy-relevant learning that can assist countries to achieve Sustainable Development Goal 3: ensure healthy lives and promoting well-being for all at all ages by 2030.
\end{abstract}

Keywords: Asia Pacific, comparative analysis, health policy analysis, health system reviews, health systems

\section{Background}

The United Nations has urged countries to set national targets for strengthening their health systems, in order to achieve Sustainable Development Goal 3 (SDG 3): ensure healthy lives and promote well-being for all at all ages by 2030. ${ }^{1}$ Many low- and middle-income countries in the World Health Organization (WHO) South-East Asia and Western Pacific Regions will struggle to reach the SDG 3 targets by 2030, including achieving universal health coverage and responding to the increasing burden of noncommunicable diseases. Achieving universal health coverage for their populations, for example, requires financial risk protection, equitable access to health care, and effective services and medicines. ${ }^{2}$ Policy-makers therefore need knowledge on what works, why, and in what settings, in order to consider what might be the best strategy for reaching their agreed SDG health targets. While the countries and areas of these two WHO regions are diverse in population, culture, size and socioeconomic status, they have in common many health system challenges.
Low- and middle-income countries encounter an information gap, since much of the research on health systems comes from high-income countries. ${ }^{3}$ A complex entity such as a health system is not easy to review. A study may cover how a country plans, manages and finances activities to improve the health of its population; identify the many different actors and key organizations; and analyse functions such as regulation, financing and delivery of services. ${ }^{4}$ Further, in comparing health system structures and interventions across multiple countries, a research approach must consider political and societal concerns and technical and clinical factors, as well as methodological issues. ${ }^{5,6}$

This paper proposes a framework for the analysis of health systems of multiple countries, using examples from some of the studies published by the Asia Pacific Observatory on Health Systems and Policies (hereafter referred to as the Asia Pacific Observatory). Established in 2011 in order to provide a regional resource for information and evidence on health system reforms, ${ }^{7}$ its partners include the WHO Regional Offices for South-East Asia and for the Western Pacific, international agencies (Asian Development Bank, World Bank), 
and currently eight governments (Australia, Fiji, Hong Kong Special Administrative Region, Republic of Korea, Republic of the Philippines, Singapore, Sri Lanka and Thailand). The Asia Pacific Observatory covers the 38 countries and areas of the WHO South-East Asia and WHO Western Pacific Regions. The work is undertaken by a secretariat (currently based in the WHO Regional Office for South-East Asia) and three research centres, each with an associated network of researchers and research institutes. These observatory research centres are based at the Melbourne University Nossal Institute in Australia, Duke Kunshan University in China, and a joint programme between the Ministry of Public Health in Thailand, and the University of Tokyo in Japan. Examples in this paper are drawn from three types of reports published by the Asia Pacific Observatory:

- health system reviews, published as "Health Systems in Transition" profiles, which offer a comprehensive description and analysis of the health system of a country, using a standardized template, with reports published so far on 16 countries (as at 1 December 2017) and several others under way;

- comparative country studies, which compare two or more countries with regard to a regional health system issue, drawing on databases, literature reviews and interviews with in-country informants; published studies include topics such as strategic purchasing, hospital payment methods, the governance of public hospitals, and health system responses to noncommunicable diseases;

- policy briefs, which are short reports that synthesize evidence from the international literature and from country experiences in relation to regional policy challenges; topics so far include mortality statistics, universal health coverage for informal workers, out-of-pocket payments, purchasing from the private sector, health technology assessment, quality health care and dual professional practice.

\section{Comparative analysis: methodological issues}

Comparison is a universal research method: for example, A compared to B; before versus after; control versus experimental group. A comparative approach can test assumptions about how well a system, a policy or a procedure works in different contexts: is my way the right way? Comparing different countries can suggest new ideas and new ways of doing things: might that work in my country? Comparison increases explanatory power for inductive reasoning: would a successful policy in one country work in another? It also increases the power of a deductive explanation: are there exceptions to a generalization?

While there are good reasons to undertake comparative studies, it is wise to draw cautious conclusions. What works well in one country may not work so well in another, and any policy transplant will almost certainly require modifications. Understanding the context and culture of a country is crucial when reviewing a health system, interpreting the statistics or proposing health system reforms. ${ }^{8}$ This understanding is particularly important in the diverse region covered by the Asia Pacific Observatory.
Use of performance indicators is a common method for comparing health systems. The countries covered by the Asia Pacific Observatory have limited comparable statistics, however, compared to the "health for all" database of the WHO European Region and Organisation for Economic Cooperation and Development (OECD) databases. For example, the national health accounts framework used by high-income countries, ${ }^{9}$ is not necessarily feasible for some other countries. While it is important to know how much was spent and on what, it is also important to know whether the money was spent well in delivering quality services, which is a much harder question to answer. Sources of data available to a varying extent to support health system comparisons in the region include WHO country reports and national health management information systems, while internationally comparable sources include world health statistics, ${ }^{10}$ world development indicators ${ }^{11}$ and demographic and health surveys. ${ }^{12}$

A health system profile may be based on a crosssectional snapshot or a time-series measure, and clearly both approaches are useful. A composite "single number" assessment and ranking of national health systems, however, as produced in the seminal World health report $2000,{ }^{13}$ has not been repeated. Nor is a classical "gold standard" approach to research on health systems much used, since health systems or their components cannot easily be assigned to random double-blind trials; therefore, comparative research does offer a way to control for some variables.

Criteria for evaluating a health system are also explored in some analytic studies, such as equity, effectiveness and efficiency. Such abstract concepts are contested, however, and require multiple indicators. Equity may be measured, for example, by factors such as income inequality, access to health care and health outcomes. ${ }^{14}$ Classifications of health systems within a typology is another common approach. For example, a study of 30 OECD health-care systems classified these according to three core dimensions (regulation, financing and service provision), and three types of actors (state, societal and private actors). This classification produced five system types: national health service, national health insurance, social health insurance, etatist social health insurance and private health systems. ${ }^{15}$ The diverse health systems of the countries covered by the Asia Pacific Observatory, however, mostly use mixed methods of funding and service delivery, so not all fit neatly within a specific typology.

\section{Framework of research approaches for comparing health systems}

A framework offers a way to consider different approaches for studying and comparing health systems across two or more countries. This paper proposes a framework based on seven types of study categories that use a variety of methods: for example, standardized case-studies, descriptive analysis, statistical analysis and policy analysis (see Table 1). Most of these study categories use multiple research methods, which are both quantitative and qualitative. The approaches In Table 1 are drawn from types of study categories and associated methods that are common in cross-national comparative studies. While this paper focuses on comparative research, the framework could also be used to organize a systematic 
Table 1. Framework of research approaches for comparing health systems

\begin{tabular}{|c|c|c|c|}
\hline Study category & $\begin{array}{l}\text { Study examples from the Asia } \\
\text { Pacific Observatory }\end{array}$ & Main methods & Focus of studies \\
\hline National health systems & $\begin{array}{l}\text { "Health Systems in Transition" } \\
\text { reviews }\end{array}$ & $\begin{array}{l}\text { Case-study comparisons using } \\
\text { standardized format, literature } \\
\text { review, statistical databases, } \\
\text { performance indicators, key } \\
\text { informants }\end{array}$ & $\begin{array}{l}\text { Differences/similarities, distinctive } \\
\text { features, benchmarking, rankings }\end{array}$ \\
\hline Population groups & $\begin{array}{l}\text { People with chronic conditions or } \\
\text { disabilities and older people }\end{array}$ & $\begin{array}{l}\text { Statistics (define, measure, } \\
\text { compare), performance indicators, } \\
\text { literature review, surveys, key } \\
\text { informants and focus groups }\end{array}$ & $\begin{array}{l}\text { Incidence, prevalence, health status, } \\
\text { service use, health outcomes }\end{array}$ \\
\hline $\begin{array}{l}\text { Health system functions } \\
\text { and components }\end{array}$ & $\begin{array}{l}\text { Financing, e.g. provider payments; } \\
\text { service delivery, e.g. quality of care }\end{array}$ & $\begin{array}{l}\text { Description, statistics, causative } \\
\text { relationships, key informants }\end{array}$ & $\begin{array}{l}\text { Inputs and processes, and criteria } \\
\text { such as efficiency access }\end{array}$ \\
\hline Institutions & $\begin{array}{l}\text { Public hospital governance, health } \\
\text { technology assessment agencies }\end{array}$ & Case-studies using multiple methods & $\begin{array}{l}\text { Organizational structures, different } \\
\text { responses to similar issues }\end{array}$ \\
\hline Health policy & Dual professional practice & $\begin{array}{l}\text { Literature review, policy analysis, } \\
\text { policy dialogue workshops }\end{array}$ & $\begin{array}{l}\text { Problem definition, values, policy } \\
\text { development, implementation, } \\
\text { outcomes }\end{array}$ \\
\hline Programmes & $\begin{array}{l}\text { Primary health-care responses to } \\
\text { noncommunicable diseases }\end{array}$ & $\begin{array}{l}\text { Description and statistics, systematic } \\
\text { literature review, key informants }\end{array}$ & $\begin{array}{l}\text { Structure, distribution, procedures, } \\
\text { outcomes }\end{array}$ \\
\hline Health system theory & Out-of-pocket payments & Hypothesis testing & $\begin{array}{l}\text { Health service access, equity and } \\
\text { effectiveness outcomes }\end{array}$ \\
\hline
\end{tabular}

analysis of a single country, ranging from a comprehensive health system overview down to more focused studies of a health system function, such as financing arrangements, or a component, such as a ministry of health.

\section{National health systems: "Health Systems in Transition" reviews}

Many low- and middle-income countries lack an overview report on their health system. The "Health Systems in Transition" reviews published by the Asia Pacific Observatory are often the first occasion when the components and connections of a country's health system are comprehensively mapped and analysed. The purpose of these profiles is to unpack the elements of a health system in a way that makes clear how these resources, structures and arrangements are put together to deliver health services to the population. Casestudies with a standardized format are readily understood and also facilitate comparative research. The Commonwealth Fund based in New York, for example, regularly compares the health system in the United States of America to that of other OECD countries. ${ }^{16}$ Cross-national case-studies often focus on countries with somewhat similar systems and cultures, such as high-income countries in east Asia, ${ }^{17}$ or less frequently may compare two or more very different health systems in order to highlight distinctive aspects. Another approach compares the health systems of a particular region; for example, the Asia Pacific Observatory has begun to review the smaller Pacific Island nations (about 12 countries) such as Fiji, ${ }^{18}$ Tonga, ${ }^{19}$ Solomon Islands ${ }^{20}$ and Papua New Guinea (under way).

The case-study format used by the Asia Pacific Observatory was adapted from a template developed by the European Observatory on Health Systems and Policies. ${ }^{21}$ The accompanying guidance defines and explains the concepts and sets out the functions and components of a health system under broad headings: country context (political and economic, demographic and epidemiological, and history of health system development), organization and governance, financing, physical and human resources, delivery of services, principal health reforms, and overall health system assessment. Statistical tables include cross-sectional and time-series data, and also comparative data, such as health expenditure as a percentage of gross domestic product for selected countries. Each case-study follows the same format in describing a health system's structure and functions. A case-study provides the "building blocks" for later in-depth comparative analyses of specific aspects, such as immunization programmes or hospital licensing. These reviews are written by in-country experts, supported by observatory researchers as co-authors and/or editors.

The observatory attaches a high priority to building the capacity of experts within a country to undertake an overview and analysis of their own health-care system. The method primarily used in producing a case-study is secondary analysis (reviews of published literature, website material, internal ministry of health reports, internal reports from international agencies such as WHO and the World Bank, and statistics and performance indicators from internal and international databases). In addition, the review draws on a key informant method whereby the in-country authors canvas the views of other experts, principally researchers and policy-makers within the country.

The health systems of countries often possess distinctive features of interest to the region and beyond. For example, after years of devastation and isolation, Cambodia is in the process of reforming its health system with the Kingdom of Cambodia health system review, written in parallel with The Third Health Strategic Plan 2016-2020. ${ }^{23}$ The review drew upon in-country input by a team of authors, including from the Ministry of Health, the National Institute of Public Health and development partners. ${ }^{22}$ Indonesia's decentralization policies are of regional interest, as are its efforts to deliver health services across its archipelago of islands. ${ }^{24}$ As a country of global significance with major health reforms under way, the People's Republic of China health system review is an 
Healy et al.: Comparative analysis of health systems

important publication. ${ }^{25}$ Thailand is also of particular interest as a regional leader in achieving universal health coverage. ${ }^{26}$

Population groups: people with chronic conditions or disabilities and older people

Changing population health needs call for health systems to redirect investments and services. Two major transitions under way, for example, are an increase in noncommunicable diseases, ${ }^{27}$ and growing numbers of people aged 60 years and over. ${ }^{28}$ According to the Global Burden of Disease Study, low- and middle-income countries over the coming decade can expect a rapid rise in noncommunicable diseases, partly associated with population ageing. ${ }^{29}$ Several methods were used to produce a study of health system responses to noncommunicable diseases by middle-income and rapidly ageing countries in Asia, particularly Sri Lanka and Thailand. ${ }^{30}$ The study, a collaboration between Australian National University researchers and partners in Sri Lanka and Thailand, drew on in-country and international databases, a review of published literature and demographic and epidemiological data. The in-country authors also conducted about 20 key informant interviews with policy-makers and practitioners in each of the countries. Health services, and especially hospitals, in these countries historically were designed to respond to infectious disease and to acute and episodic care for younger patients. Beliefs and attitudes of health professionals and patients in the two countries related to ageing and illness differed somewhat. The management of people with chronic conditions and the often complex needs of older patients call for reorientation of service delivery and development of better integrated services for conditions such as diabetes and stroke. Thailand, in particular, is in the process of strengthening primary care as the level of health care best placed to respond to elderly patients, to intervene early in chronic conditions, and to provide ongoing management.

Health system functions and components: financing and service delivery

The observatory template for a health system review defines and describes the different functions and components or building blocks of a health system, such as governance, financing, staffing and service delivery arrangements. ${ }^{21}$ However, a comprehensive analysis of one of these aspects, such as financing, requires a more in-depth and nuanced study. Financing is of course a major challenge for all health systems, but particularly for low- and middle-income countries. A perennial issue is how best to fund/pay hospitals, in order to facilitate cost-effective health care. One study has shown that a number of middle-income countries covered by the Asia Pacific Observatory are considering or introducing casebased payment methods. ${ }^{31}$ This study, led by the Melbourne University Nossal Institute, engaged international experts to write review chapters on different countries and different aspects of case-based payment systems. ${ }^{31}$ The conclusions were that many countries are in transition to new providerpayment methods. A previous overreliance on fee-for-service is giving way, gradually, to capitation and case-based payment methods, including diagnosis-related groups. Implementation capacity is a limiting factor, however, as new methods must be phased in and supported by increased management and monitoring.

In order to redress limited empirical work in the region, a study aimed to critically examine purchasing arrangements in China, Indonesia and the Philippines. The study examined relationships between purchasers and providers, based on an agreed conceptual framework, which identified factors that enable or hinder effective purchasing, and produced recommendations to promote universal health coverage. ${ }^{32}$ The study used similar methods in each of the three countries, including an extensive review of documents, supplemented by informant interviews. The China case-study, undertaken by researchers at Peking University and Shandong University, examined a new mandatory insurance scheme for the entire Chinese rural population, using information collected in Qinghai and Henan provinces (six towns in each province). The methods included a review of policy documents of the central, provincial and local governments and informant interviews in each province. The Indonesia case-study on the single pool mandatory health insurance scheme for low-income groups, government and company employees, by researchers from Gadjah Mada University, examined purchaser relationships between the national social security scheme and two district health offices within each of three provinces. The methods included a document review and interviews and focus group discussions with the actors involved (government officers, provider groups, health professionals and community representatives). The Philippines case-study, by researchers from the Philippine Institute for Development Studies, examined the purchasing arrangements undertaken by the single pool mandatory national health insurance scheme (PhilHealth) that currently covers nearly $75 \%$ of the population. The study analysed the relationships between the purchaser (PhilHealth) and providers, the purchaser and citizen members, and the purchaser and government.

While much more attention is being paid to the quality of health care in high-income countries, ${ }^{33}$ less is known about lowand middle-income countries, despite the quality of health care being widely regarded as inadequate. ${ }^{34}$ Researchers from the Melbourne University Nossal Institute undertook a meta-review of systematic literature reviews on the quality of ambulatory care, and a literature review of selected strategies relevant to low- and middle-income countries. The study identified potential options for improving the quality of ambulatory care for patients in countries covered by the Asia Pacific Observatory, using approaches to improve delivery, such as contracting, social franchising and pay-for-performance. ${ }^{35}$

Institutions: public hospital governance, health technology assessment agencies

The study of key institutions is a common theme in comparative research. Why does one type of organization work well in one country but flounder in another? The vexed question of how best to govern public hospitals is an important issue in countries where state agencies have limited powers. A comparative study of public hospital governance in seven countries (India, Indonesia, New Zealand, Philippines, Sri Lanka, Thailand, Viet Nam), edited by staff of the observatory and the Nossal Institute, engaged national authors from each country. Each country case-study used similar methods: a 
common conceptual framework, a review of published papers and government documents, and semi-structured interviews with policy-makers and with managers of large public hospitals. A contextual analysis of the political and administrative history of each country was essential to understanding public hospital governance structures. The study found that many large hospitals were being given greater autonomy in the management of their finances and services. ${ }^{36}$ Fewer reforms were evident, however, in internal hospital management and clinical governance arrangements; for example, clinicians continue to predominate as hospital leaders. A comparison of health technology assessment (HTA) agencies in six countries (China, Indonesia, Republic of Korea, Malaysia, Thailand and Viet Nam) was conducted by researchers based in Thailand, with contributions from HTA practitioners in the six countries. The HTA experts discussed the political and administrative context of HTA institutions in each of their countries and reflected on five essential components identified in the literature as relevant to the establishment of HTA agencies. The study found differences between the countries in power, scope and scale, structure and procedures. ${ }^{37}$ HTA agencies in their early phase conducted ad hoc assessments with few links to policy-making, while countries with more mature HTA agencies used assessments more routinely.

Health policy: dual professional practice

Health policy analysis is a well-established field of research whose explanatory power is strengthened by comparisons across countries. Policy analysis requires a good understanding of the political context of each country, its public administration history and practice, and its policy-making processes. The observatory strategy for understanding a policy process is to partner with policy-makers and researchers within a country who engage directly in policy-making. Further, the use of policy dialogue workshops has proved a useful method across all study categories. In addition, policies developed in high-income countries need careful assessment of their relevance to other countries. ${ }^{4}$ For example, dual practice by doctors working in both government and private sectors, while common in high-income countries, is a controversial practice in low- and middle-income countries. Researchers at the Nossal Institute undertook a literature review on the extent of dual practice in 12 nations of south and east Asia. This overview, including case-studies on Thailand and Indonesia, identified three broad policy options (take no action, ban or limit dual practice, or allow dual practice). The study concluded that it was better to regulate than prohibit dual practice, in order to retain doctors in the public sector. ${ }^{38,39}$ More a literature and scoping review of existing policies than an analysis of the why and how of policy-making, the published policy brief notes that the formulation and implementation of any regulatory intervention within a country would require an in-depth study. ${ }^{38}$

\section{Programmes: primary health-care responses to} noncommunicable diseases

Programme evaluation is also a large research field that is strengthened by comparative country analysis. Primary health-care programmes must respond to context and culture in preventing or reducing risk factors associated with noncommunicable diseases. Examples of risk-factor assessment studies include reducing exposure to household smoke among children in China ${ }^{40}$ and controlling high blood pressure among adults in rural Bangladesh. ${ }^{41}$ The WHO Package of essential noncommunicable disease (PEN) interventions for primary health care in low-resource settings urges countries to adapt the tools and strategies in this package to their particular circumstances. ${ }^{42}$ Studies that apply or adapt PEN have been done or are under way in many countries, including Bhutan ${ }^{43}$ and the Democratic People's Republic of Korea. ${ }^{44}$ The observatory Duke Kunshan group has a study under way of PEN programmes in China, Nepal and Viet Nam, which is assessing the capacity of these primary healthcare systems to prevent and control cardiovascular diseases. Another study is assessing how best to mobilize community health workers (an important group of health workers in lowand middle-income countries) in combating noncommunicable diseases in Bangladesh, China, Nepal and Viet Nam. Both studies involve document reviews and survey questionnaires. They also engage with informants within each country, in order to obtain a contextual understanding and to provide solid evidence for policy development in the region.

Responding to noncommunicable diseases calls for baseline and trend measurements. However, some countries in the region still lack reliable mortality and cause-of-death data. A study by Queensland University researchers and the Health Metrics Network examined vital statistics systems in the 11 countries of the WHO South-East Asia Region and 27 countries and areas of the WHO Western Pacific Region. The method involved both a rapid assessment and a comprehensive assessment framework and the production of a composite indicator called a Vital Statistics Performance Index. This study identified three groups of countries with problematic civil registration and vital statistics collections and set out strategic pathways for achieving solutions. ${ }^{45,46}$ For example, one recommendation for group 2 (countries that record most deaths but many without a medically certified cause) was to introduce a verbal autopsy method into civil registration systems where deaths were not medically certified.

Health system theory: out-of-pocket payments

Comparative country studies offer a method for testing an explanatory theory. An example is the theory that a policy of user payment results in more responsible service use by patients and also collects needed revenue for health facilities. Many countries covered by the Asia Pacific Observatory rely heavily on out-of-pocket payments by patients and their families for goods and services, amounting to over half of the total health expenditure in some countries. An observatory study involving researchers from several countries undertook a literature review and short illustrative case-studies of countries with different contexts and varying levels of out-ofpocket payments (Cambodia, China, Fiji, Malaysia, Sri Lanka). The study concluded that out-of-pocket fees charged by health facilities in the region rarely raise substantial amounts of revenue and, crucially, have the adverse impact of preventing poor people from using health services. ${ }^{47}$

There are now more opportunities for testing ideas about how to improve health system structures, arrangements and outcomes. This is made possible by the increase in published 
research from low- and middle-income countries. The Cochrane Effective Practice and Organisation of Care group recently published four overviews of health system components that are relevant to low-income countries. ${ }^{48}$ These meta-reviews summarized 124 systematic reviews on the effects on health systems of four functions: governance, financing, delivery arrangements and implementation strategies. These systematic reviews of primary research covered varied interventions, with most research studies being on single rather multiple countries. The comparative aspect therefore emerges from an accumulation of studies. In the majority of studies, however, the evidence of impact was low or very low. While the systematic reviews uncovered large gaps in what is known, they nevertheless identified a larger volume of studies than expected, some of which can inform decisions about health systems in low-income countries. The meta-review on arrangements for service delivery found 51 systematic reviews across seven areas of delivery; for example, the question of "who provides care" identified five types of interventions, such as recruiting and retaining health workers in specific areas or types of work. ${ }^{49}$

\section{Conclusion}

No one approach can adequately explain and analyse the structures and workings of a complex health system, particularly since context is crucial to such explanations. Comparative studies of the health systems of low- and middleincome countries, such as those undertaken by the Asia Pacific Observatory, aim to increase health systems knowledge in the region, counter the overreliance upon learning from high-income countries, and avoid the danger of making the assumption that one size fits all. As evident from the observatory studies summarized in this paper, most of these studies, for reasons of resources and research capacity, rely more on a range of secondary research methods supplemented by the knowledge and experience of expert informants within a country.

As a key goal of the observatory is to inform policy-making, the strategy of engaging with in-country experts is crucial, as is the comparative analysis strategy of producing evidence that can be generalized across countries. The translation gaps between evidence, policy and practice are well known. However, an increasing body of knowledge now offers guidance on how evidence from research can be translated into formats and procedures to inform policy formulation and also to inform the implementation of these policies in practice. ${ }^{50}$

This proposed framework for comparative analysis performs two functions: it creates a list of study categories that range from a health system overview down to a more in-depth study of a particular component. Most of these study approaches are associated with multiple methods that span case-studies, statistical analysis, descriptive analysis and limited hypothesis testing. This framework gives form and structure to the analysis of health systems in a way that offers a logical process of investigation and policy-making. For example, reviews of a health system or several health systems set the scene for building a series of in-depth studies, as done in the comparative country studies and the policy briefs published by the Asia Pacific Observatory. Within this framework, the categories of study suggest the tools needed to carry out consistent and comparative health systems analysis. The comparative nature of the analysis then provides the foundation for assessing national health systems in a way that is realistic and provides the foundation for reforms based on evidence, while accounting for the local context. The conceptual framework offers an aid to undertaking comparisons across the health systems of different countries, to enable policy-makers and researchers to test assumptions and to draw lessons on what works and why, and what does not work and why.

Source of support: None.

Conflict of interest: None declared.

Authorship: JMH wrote the first draft and revised the paper, ST and WP contributed study examples and commented on the paper, PLA revised and commented on the paper.

How to cite this paper: Healy JM, Tang S, Patcharanarumol W, Annear PL. A framework for comparative analysis of health systems: experiences from the Asia Pacific Observatory on Health Systems and Policies. WHO South-East Asia J Public Health. 2018;7(1):5-12. doi:10.4103/2224-3151.228421.

\section{References}

1. United Nations. Sustainable Development Goals: 17 goals to transform our world (http://www.un.org/sustainabledevelopment/, accessed 8 January 2018).

2. World Health Organization. SDG 3: ensure healthy lives and promote wellbeing for all at all ages (http://www.who.int/sdg/targets/en/, accessed 8 January 2017).

3. World report on knowledge for better health: strengthening health systems. Geneva: World Health Organization; 2004 (http://apps.who. int/iris/bitstream/10665/43058/1/9241562811.pdf, accessed 8 January 2018).

4. Gilson L, editor. Health policy and systems research: a methodology reader. Geneva: World Health Organization; 2012 (http://apps.who. int/iris/bitstream/10665/44803/1/9789241503136_eng.pdf?ua=1, accessed 8 January 2018).

5. Marmor TR, Freeman R, Okma K. Comparative perspectives and policy learning in the world of health care. J Comp Policy Anal. 2005;7(4):331-48. doi:10.1080/13876980500319253.

6. Blank RH, Burau V. Comparative health policy, 4th ed. New York: Palgrave Macmillan; 2013.

7. Asia Pacific Observatory on Health Systems and Policies (http:// www.wpro.who.int/asia_pacific_observatory/en/, accessed 8 January 2018).

8. Healy J. Analysing health care systems performance: the story behind the statistics. Aust N Z J Public Health. 2003;27(6):642-4. doi:10.1111/j.1467-842X.2003.tb00613.x.

9. Organisation for Economic Co-operation and Development, Eurostat, World Health Organization. A system of health accounts 2011: revised edition. Paris: OECD Publishing; 2017 (http://www.oecd-ilibrary.org/ docserver/download/8117001e.pdf?expires=1515413972\&id=id\& accname=guest\&checksum=A4C42C494D20E180AE219B1AE00859B8, accessed 8 January 2018).

10. World Health Organization. Global Health Observatory (GHO) data. World health statistics (http://www.who.int/gho/publications/world_ health_statistics/en/, accessed 8 January 2018).

11. World Bank. World development indicators (http://data.worldbank.org/ products/wdi, accessed 8 January 2018).

12. United States Agency for International Development. The demographic and health surveys program (https://www.usaid.gov/ what-we-do/global-health/cross-cutting-areas/demographic-andhealth-surveys-program, accessed 8 January 2018).

13. The world health report 2000 . Health systems: improving performance. Geneva: World Health Organization; 2000 (www.who. int/whr/2000/en/whr00_en.pdf, accessed 8 January 2018). 
14. Commission on Social Determinants of Health. Closing the gap in a generation: health equity through action on the social determinants of health. Final report of the Commission on Social Determinants of Health. Geneva: World Health Organization; 2008 (http://apps.who. int/iris/bitstream/10665/43943/1/9789241563703_eng.pdf, accessed 8 January 2018).

15. Böhm K. Five types of OECD healthcare systems: empirical results of a deductive classification. Health Policy. 2013;113(3):258-69. doi:10.1016/j.healthpol.2013.09.003.

16. Mossialos E, Wenzl M, Osborn R, Sarnak D, editors. 2015 International profiles of health care systems. New York: The Commonwealth Fund; 2016 (http://www.commonwealthfund.org/ / media/files/publications/fund-report/2016/jan/1857 mossialos intl profiles_2015_v7.pdf, accessed 8 January 2018)

17. Chongsuvivatwong V, Phua KH, Yap MT, Pocock N, Hashim JH, Chhem R et al. Health and health-care systems in southeast Asia: diversity and transitions. Lancet. 2011;377:429-37. doi:10.1016/ S0140-6736(10)61507-3.

18. Roberts G, Irava W, Tuiketei T, Nadakuitavuki R, Otealagi S, Singh S et al. The Fiji Islands health system review. Manila: World Health Organization Regional Office for the Western Pacific; 2011 (Health Systems in Transition. Vol. 1, No. 1; http://apps.who.int/iris/ bitstream/10665/207503/1/9789290615439_eng.pdf?ua=1, accessed 8 January 2018)

19. Rodney A, Hufanga S, Ika V, Paasi SS, Vivili P, 'Ahio T et al. The Kingdom of Tonga health system review. Manila: World Health Organization Regional Office for the Western Pacific; 2015 (Health Systems in Transition. Vol. 5, No. 6; http://iris.wpro.who.int/bitstream/ handle/10665.1/11371/9789290617198_eng.pdf, accessed 8 January 2018).

20. Hodge N, Slatyer B, Skiller L. Solomon Islands health system review. Manila: World Health Organization Regional Office for the Western Pacific; 2015 (Health Systems in Transition. Vol. 5, No. 1; http:// apps.who.int/iris/bitstream/10665/208212/1/9789290616931_eng. pdf?ua $=1$, accessed 8 January 2018)

21. Asia Pacific Observatory on Health Systems and Policies and European Observatory on Health Systems and Policies. Health systems in transition. Template for authors: as adapted for use in the Asia Pacific Region. Manila: World Health Organization Regional Office for the Western Pacific; 2015 (http://iris.wpro.who.int/bitstream/ handle/10665.1/10506/9789290616672_eng.pdf, accessed 8 January 2018).

22. Annear PL, Grundy J, Ir P, Jacobs J, Men C, Nachtnebel M et al. The Kingdom of Cambodia health system review. Manila: World Health Organization Regional Office for the Western Pacific; 2015 (Health Systems in Transition. Vol. 5, No. 2; http://apps.who.int/ iris/bitstream/10665/208213/1/9789290616917_eng.pdf, accessed 8 January 2018)

23. Department of Planning and Health Information. The Third Health Strategic Plan (HSP3) 2016-2020: "quality, effective and equitable health services". Phnom Penh: Ministry of Health; 2016 (http:// www.nationalplanningcycles.org/sites/default/files/planning_cycle repository/cambodia/cambodia_nhpsp_2016-2020.pdf, accessed 8 January 2017)

24. Mahendradhata $Y$, Trisnantoro L, Listyadewi S, Soewondo $P$, Marthias T, Harimurti P et al. The Republic of Indonesia health system review. Manila: World Health Organization Regional Office for the Western Pacific; 2017 (Health Systems in Transition. Vol. 7, No. 1; http://apps.who.int/iris/bitstream/10665/254716/1/9789290225164eng.pdf, accessed 8 January 2018).

25. Meng Q, Yang H, Chen W, Sun Q, Liu X. People's Republic of China health system review. Manila: World Health Organization Regional Office for the Western Pacific; 2015 (Health Systems in Transition. Vol. 5, No. 7; http://iris.wpro.who.int/bitstream/

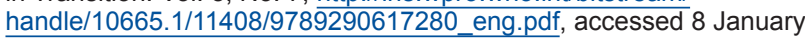
2018).

26. Jongudomsuk $P$, Srithamrongsawat $S$, Patcharanarumol W, Limwattananon S, Pannarunothai S, Vapatanavong $P$ et al. The Kingdom of Thailand health system review. Manila: World Health Organization Regional Office for the Western Pacific; 2015 (Health Systems in Transition. Vol. 5, No. 5; http://apps.who.int/iris/ bitstream/10665/208216/1/9789290617136_eng.pdf, accessed 8 January 2018)

27. Global status report on noncommunicable diseases 2014. Geneva: World Health Organization; 2014 (http://apps.who.int/iris/ bitstream/10665/148114/1/9789241564854_eng.pdf, accessed 8 January 2018).
28. World report on ageing and health. Geneva: World Health Organization; 2015 (http://apps.who.int/iris/ bitstream/10665/186463/1/9789240694811_eng.pdf, accessed 8 January 2018)

29. Institute for Health Metrics and Evaluation. Global burden of disease (http://www.healthdata.org/gbd, accessed 8 June 2018).

30. Yiengprugsawan $\mathrm{V}$, Healy J, Kendig $\mathrm{H}$, editors. Health system responses to population ageing and noncommunicable diseases in Asia. Manila: World Health Organization Regional Office for the Western Pacific; 2016 (Comparative Country Studies. Vol. 2, No. 2; http://apps.who.int/iris/bitstream/10665/252738/1/apo-ccs-ageing5b. pdf?ua=1, accessed 8 January 2018).

31. Annear PL, Huntington $D$, editors. Case-based payment systems for hospital funding in Asia: an investigation of current status and future directions. Manila: World Health Organization Regional Office for the Western Pacific; 2015 (Comparative Country Studies. Vol. 1, No. 2; http://apps.who.int/iris/bitstream/10665/208246/1/9789290617327 eng.pdf, accessed 8 January 2018).

32. Honda A, Di Mclntyre D, Hanson K, Tangcharoensathien V, editors. Strategic purchasing in China, Indonesia and the Philippines. Manila: World Health Organization Regional Office for the Western Pacific; 2016 (Comparative Country Studies. Vol. 2, No. 1; http://apps.who. int/iris/bitstream/10665/252763/1/9789290617686-eng.pdf, accessed 8 January 2018).

33. Davis K, Stremikis K, Squires D, Schoen C. Mirror, mirror on the wall: 2014 update: how the performance of the U.S. health care system compares internationally. New York: Commonwealth Fund; 2014 (http://www.resbr.net.br/wp-content/uploads/historico/ Espelhoespelhomeu.pdf, accessed 8 January 2018).

34. Akachi Y, Kruk ME. Quality of care: measuring a neglected driver of improved health. Bull World Health Organ. 2017;95:465-72. doi:10.2471/BLT.16.180190.

35. Dayal P, Hort K. Quality of care: what are effective policy options for governments in low- and middle-income countries to improve and regulate the quality of ambulatory care? Manila: World Health Organization Regional Office for the Western Pacific; 2015 (Policy Brief. Vol. 4, No. 1; http://apps.who.int/iris/ bitstream/10665/208217/1/9789290616955_eng.pdf, accessed 8 January 2018).

36. Huntington D, Hort K, editors. Public hospital governance in Asia and the Pacific. Manila: World Health Organization Regional Office for the Western Pacific; 2015 (Comparative Country Studies. Vol. 1, No. 1; http://apps.who.int/iris/bitstream/10665/208218/1/9789290617112 eng.pdf?ua=1, accessed 8 January 2018)

37. Chootopongchaivat S, Tritasvit N, Luz A, Teerawattananon $\mathrm{Y}$, Tantivess S. Factors conducive to the development of health technology assessment in Asia: impacts and policy options. Manila: World Health Organization Regional Office for the Western Pacific; 2015 (Policy Brief. Vol. 4, No. 2; http://apps.who.int/iris/ bitstream/10665/208261/1/9789290617341_eng.pdf, accessed 8 January 2018).

38. Hipgrave D, Nachtnebel M, Hort K. Dual practice by health workers in South and East Asia: impacts and policy options. Manila: World Health Organization Regional Office for the Western Pacific; 2013 (Policy Brief. Vol. 2, No. 1; http://apps.who.int/iris/ bitstream/10665/206912/1/9789290616238 eng.pdf, accessed 8 January 2018).

39. McPake B, Russo G, Hipgrave D, Hort K, Campbell J. Implications of dual practice for universal health coverage. Bull World Health Organ. 2016;94:142-6. doi:10.2471/BLT.14.151894.

40. Abdullah AS, Hua F, Khan H, Xia X, Bing Q, Tarang K et al. Secondhand smoke exposure reduction intervention in Chinese households of young children: a randomized controlled trial. Acad Pediatr. 2015;15(6):588-98. doi:10.1016/j.acap.2015.06.008.

41. Jafar TH, Silva Ad, Naheed A, Jehan I, Liang F, Assam PN et al.; COBRA-BPS Study Group. Control of blood pressure and risk attenuation: a public health intervention in rural Bangladesh, Pakistan, and Sri Lanka: feasibility trial results. J Hypertens. 2016;34(9):1872-81. doi:10.1097/HJH.0000000000001014.

42. Package of essential noncommunicable disease (PEN) interventions for primary health care in low-resource settings. Geneva: World Health Organization; 2010 (http://www.who.int/nmh/publications/ essential_ncd_interventions_Ir_settings.pdf, accessed 8 January 2018). 
Healy et al.: Comparative analysis of health systems

43. Wangchuk D, Virdi NK, Garg R, Mendis S, Nair N, Wangchik D et al. Package of essential noncommunicable disease (PEN) interventions in primary health-care settings in Bhutan: a performance assessment study. WHO South-East Asia J Public Health. 2014;3(2):154-60. doi:10.4103/2224-3151.213794.

44. Hyon CS, Nam KY, Sun HC, Garg R, Shrestha SM, Ok KU et al. Package of essential noncommunicable disease (PEN) interventions in primary health-care settings in the Democratic People's Republic of Korea: a feasibility study. WHO South-East Asia J Public Health. 2017;6(2):69-73. doi:10.4103/2224-3151.213794.

45. Mikkelsen L, Rampatige R, Hernandez B, Lopez AD. Strengthening vital statistics systems. What are the practical interventions necessary to reduce ignorance and uncertainty about causes of death and disease burden in the Asia Pacific region? Manila: World Health Organization Regional Office for the Western Pacific; 2014 (Policy Brief. Vol. 3, No. 2; http://apps.who.int/iris/ bitstream/10665/208224/1/9789290616870_eng.pdf?ua=1, accessed 8 January 2018)

46. Rampatige R, Mikkelsen L, Hernandez B, Riley I, Lopez AD Hospital cause-of-death statistics: what should we make of them? Bull World Health Organ. 2014;92(1):3-3A. doi:10.2471/ BLT.13.134106.

47. Kwon S, Meng Q-Y, Tangcharoensathien V, Limwattananon S, James CD. Direct household payments for health services in Asia and the Pacific: impacts and policy options.

Manila: World Health Organization Regional Office for the Western Pacific; 2012 (Policy Brief; http://apps.who.int/iris/ bitstream/10665/207512/1/9789290615651_eng.pdf?ua=1, accessed 8 January 2018).

48. Ranson MK, Evans DB. Taking health systems research syntheses to the next level: overviews of systematic reviews. Cochrane Database Syst Rev. 2017;9:ED000123. doi:10.1002/14651858.

49. Ciapponi A, Lewin S, Herrera CA, Opiyo N, Pantoja T, Paulsen E et al. Delivery arrangements for health systems in low-income countries: an overview of systematic reviews. Cochrane Database Syst Rev. 2017;9:CD011083. doi: 10.1002/14651858.CD011083.pub2.

50. Lavis JN, Røttingen JA, Bosch-Capblanc, Atun R, El-Jardali F Gilson $L$ et al. Guidance for evidence-informed policies about health systems: linking guidance development to policy development. PLoS Med. 2012;9(3):e1001186. doi:10.1371/journal.pmed.1001186. 